\title{
Physical activity preferences of older home care clients
}

Short running title: Physical activity preferences of home care clients

Elissa Burton, BSc (Hons), MBus ${ }^{1,2}$

Gill Lewin, PhD, MPH, MSc, BSc (Hons) ${ }^{2,3}$

Duncan Boldy, PhD, MSc, CertEd, BSc (Hons) ${ }^{3}$

${ }^{1}$ School of Physiotherapy \& Exercise Science, Curtin University, Perth, Western Australia, Australia

${ }^{2}$ Silver Chain, Osborne Park, Western Australia, Australia

${ }^{3}$ School of Nursing \& Midwifery, Curtin University, Perth, Western Australia, Australia

Corresponding Author:

Elissa Burton. School of Physiotherapy \& Exercise Science, Curtin University, GPO Box U1987, Perth, Western Australia, Australia, 6845.

Email: E.Burton@curtin.edu.au

Telephone: +61 892667993 .

Manuscript word count: 4474 (not including, abstract, keywords, questions or references) 


\begin{abstract}
AUTHOR'S NOTE
Acknowledgements

The authors thank the clients from Silver Chain who kindly agreed to be involved in the study and the Senior Researcher from the Curtin University who assisted with data analysis.

Declaration of Conflicting Interests
\end{abstract}

There are no declared conflicts of interest.

\title{
Funding
}

This research was supported by a Curtin University Internal Research Grant. The first author was supported by a Healthway PhD scholarship and a Curtin University Top Up Scholarship.

\section{Contributions to the Manuscript}

Study design: EB, GL, DB; data collection: EB; analysis: EB, GL, outside Senior Researcher; manuscript preparation: EB; critical revision of the manuscript: GL, DB. 


\title{
Physical activity preferences of older home care clients
}

\begin{abstract}
Background: Physical activity contributes to an older person's health and wellbeing by maintaining strength, balance and mobility, all of which are important for older people who wish to remain living in their home for as long as possible. It is therefore essential that community nurses and those working with home care clients promote being physically active. To do this effectively requires an understanding of the type of physical activity older home care clients prefer to engage in.

Aim: The aims of this study were to identify the physical activity preferences of older people who received a home care service, and to determine whether being physically active is important to this population.
\end{abstract}

Methods: Twenty older home care clients were interviewed using a semi-structured interview schedule. Data were analysed using a descriptive qualitative methodology.

Results: Walking, housework and gardening were identified as the activities of choice. The majority of interviewees suggested that it was important to be physically active.

Conclusion: Structured exercise programs are not the activity of choice for older home care clients. Therefore, when community nurses and allied health workers promote physical activity to their clients they should suggest activities such as walking, housework and gardening, and also endorse the benefits of physical activity for wellbeing and staying independent.

Implication for Practice: Health and community nurses and organisations should routinely encourage home care clients to increase their activity levels, especially utilising those activities they most enjoy.

\section{Keywords}

Active ageing, home and community care, nursing, exercise, health promotion, older people. 


\section{Summary Statement}

\section{What does this research add to existing knowledge in gerontology?}

- Although older people might be receiving home care services, many are still able to be active. Health and community nurses delivering services to these clients should promote being physically active to help maintain independence and increase function, health and wellbeing.

- Walking and completing everyday activities such as gardening, housework and shopping are the activities of choice for older people receiving home care services.

\section{What are the implications of this new knowledge for nursing care with older people?}

- When older home care clients suggest they dislike exercise and sport, community nurses should encourage them to be more physically active through activities they enjoy, such as gardening or walking with their family or friends.

- When discussing a client's care with family members, it is important for health and community nurses to promote the benefits of the client being physically active, in terms of their independence, wellbeing and self-esteem, rather than from a negative, risk perspective.

\section{How could the findings be used to influence policy or practice or research or education?}

- Health and community care organisations should consider delivering more physical activity programs within their services and promote the benefits of being physically active to their clients and families on a regular basis, to assist them in living independently for longer, and possibly reduce the amount of ongoing services needed. 
- Further research needs to be undertaken to determine whether a lifestyle activity program, where exercise is incorporated into a person's daily routines, is as effective as the structured exercise programs usually delivered to older home care clients. 


\section{Physical activity preferences of older home care clients}

\section{Introduction}

Australia's population is ageing and as the baby boomer generation embarks on retirement, Australia's older population will increase in numbers to a proportion of the total population not previously seen. Over one million older Australians currently receive home care services, such as personal care (showering, dressing), nursing care (wound care, pain management), home help (cleaning and gardening) and palliative care, and by 2050 that number is estimated to rise to 3.5 million (Productivity Commission 2011).

There are a number of different types of home care services available to older people in Australia which range from short term nursing care to long term domestic assistance and personal care. Many home care service providers complete the tasks for the older person, with no encouragement or expectation of the client that they try and maintain their functional ability to help them live in their home longer (Ryburn, Wells et al. 2009). Long term home care services, such as domestic assistance and personal care, cost the government millions of dollars in funding. The anticipated rise in the number of older Australians needing home care services in the future, together with community and stakeholder concerns about the functioning of the

existing aged care system, led the previous Australian government to fund an inquiry into how the system could be improved for the future. This review recommended quite radical reform, including a change from a system focused on providing care, to a system focused on wellness and enhancing older people's independence and wellbeing (Productivity Commission 2011). Being physically active plays an important role in this process.

Physical activity is often described as "any bodily movement produced by skeletal muscle that results in energy expenditure" (Saarloos, Nathan et al. 2008, p. 79) and encompasses all activity, such as walking for transport or cleaning the house. Whereas, exercise is defined as 
"a subset of physical activity consisting of planned, structured, repetitive bodily movements with the purpose of improving or maintaining one or more components of physical fitness or health (Dishman, Heath et al. 2013, p. 559). Examples of exercise may be a workout at the gym using weights and an exercise bike or completing exercises suggested by a physiotherapist that can be completed in the home.

There is a vast amount of evidence supporting the role of physical activity in assisting older people to regain or better maintain mobility and functional independence (Paterson and Warburton 2010; Liu and Latham 2011; Dishman, Heath et al. 2013). As well as reducing the risk of chronic illness, minimising the risk of falls and feeling better mentally (reduced negative moods, higher positive moods, lower anxiety levels), and physically, it is necessary to sustain strength, balance and mobility in the latter years to live independently without assistance (Michael, Lin et al. 2010; Gillespie, Robertson et al. 2012; Robertson, Robertson et al. 2012).

With the exception of restorative home care services, few standard Australian home care services offer support in initiating or maintaining activity for the older person. Therefore, if we are to design services that are effective in helping home care clients to initially increase and then maintain their activity levels we need to understand their attitudes towards activity, including whether they recognise the importance of being physically active and what activities they enjoy doing the most.

Studies have examined older community dwelling people's attitudes to, and preferences for activity. They found that for older people living in Australia and England, walking and gardening (including weeding, mowing lawns, sweeping paths and trimming trees and shrubs) were their preferred way of being physically activity, with participation in sport and more vigorous exercise decreasing with age (Saarloos, Nathan et al. 2008; Townsend, Bhatnagar et al. 2012). Saarloos et al. (2008) reported less than $10 \%$ of their study participants aged over 65 
years participated in sports, such as swimming (8.5\%), aerobics (8.4\%) and golf $(6.3 \%)$, whereas $57 \%$ reported walking for exercise.

Other studies have explored perceptions of ageing and physical activity and found housework and gardening to be as popular as activities such as Tai Chi and walking (Belza, Walwick et al. 2004; Lowe, Watanabe et al. 2010; Koo 2011). These studies have considered community dwelling older people as a whole (Welmer, Morck et al. 2012) or specific groups such as palliative care patients (Lowe, Watanabe et al. 2010). However, no research has identified the physical activity preferences (what they choose to do) of older people receiving home care services (who are functionally impaired), or whether they perceive being physically active as important. Given the current and projected population that require home care services, this study aims to fill this important gap in knowledge. It will also provide community nurses, physiotherapists and occupational therapists who deliver care to this population, a better understanding of their clients' likely activity preferences and thus enable them to suggest ways of becoming more active that have a greater likelihood of being maintained in the longer term.

The research questions asked in this study were: what are older home care clients' preferred physical activities and do they think physical activity is important for health and wellbeing.

\section{Methods}

\section{Study design}

This was a qualitative study involving semi-structured interviews of clients who had received home care services between 2006 and 2009 from Silver Chain, one of Western Australia's largest community health and aged care organisations. This current study formed part of a larger study which used a questionnaire as well as the interviews reported on here, to 
investigate levels of physical activity and identify barriers and motivators to being physically active for older home care clients (Burton, Lewin et al. 2013; Burton, Lewin et al. 2013).

\section{Participants}

The population from which the main study sample was drawn included 9,199 past and present home care clients. Inclusion criteria included: aged 70 years and over; having received a minimum of four weeks or four visits of home care; and living in the community. Exclusion criteria were not being able to communicate in English or having been diagnosed with dementia. The questionnaire incorporated a number of tools including the Physical Activity Scale for the Elderly (PASE), the SF-12v2@ Health Survey, and the Geriatric Depression Scale-5 (GDS-5). The PASE is a 12-item survey designed to assess physical activity levels, including household activity, in large samples of older people over a seven day period (Washburn, McAuley et al. 1999). PASE scores are calculated based on activity frequency and an activity-weighted score multiplied by frequency (Washburn, Smith et al. 1993). PASE scores range from 0-400 with higher scores meaning higher physical activity levels.

Fifteen hundred clients were randomly selected from the study sample and received a questionnaire in the mail. One hundred and ninety participants expressed an interest, via a question within the questionnaire, in being interviewed. Then names of these individuals, their age and physical activity status (active or not active), based on their PASE score from the questionnaire, were entered into a database. Selection of the 20 participants to be interviewed was based on a purposive sampling approach aimed at 'range' and 'variety', related to age and physical activity level.

Of the 20 initially selected, four were replaced. The reasons were: not interested anymore (2); did not speak or understand English well (1); and had died (1). 


\section{Data collection process}

Prospective participants were sent a letter, together with a consent form and information sheet. The letter explained that they would be contacted by phone in the coming days to confirm their interest and to set a time, date and place for the interview. With one exception, all interviews were conducted in people's homes (the other was by phone) between July and September 2010. In two cases, the spouse of the participant also took part. Prior to commencement, the interviewer took some time to ensure that the participant understood the study, was able to answer questions coherently and was happy to be interviewed. The researcher then obtained their written consent and permission to tape record the interview.

Interview times ranged from 20-90 minutes, with one researcher only being involved. Prior to undertaking the study the researcher had undertaken qualitative interview training and been supervised by an experienced qualitative researcher for some three years.

The interview schedule was designed to provide structure and maintain focus on the participants' physical activity preferences and their opinions on the importance of being physically active. Some of the questions were only of relevance to the larger study (see questions asterisked in Figure 1), however all interview data was analysed and where applicable to the research questions of this study the data were utilised. At times participant answers required further explanation and in these cases additional questions not included in the full interview schedule were asked. Figure 1 outlines the interview schedule.

\section{Ethics}

Ethics approval for the study was granted by the Curtin University and Silver Chain Human Research Ethics Committees.

\section{Data analysis}


Analysis of the interview data followed the approach of Bazeley (2009) who recommended the use of matrices to display data and examine patterns. In this paper matrices were used to facilitate comparative analysis and assist in drawing conclusions over a number of stages and levels of analysis. Content analysis was conducted in four stages and produced two levels of data (elements and concepts). Taped interviews were replayed and interview summaries developed by the researcher (stage 1). This involved transcribing the majority of interviews verbatim, omitting sections irrelevant to the topic. Transcription of data was undertaken by the researcher and a colleague. Qualitative data were then transferred by the researcher into an Excel spread sheet for further analysis, initially revealing a total of 602 words and phrases (stage 2). Following further examination for similarity and/or repetition, this was then reduced to 152 elements (stage 3). Elements across all interviews were then examined to identify commonality, resulting in 10 common concepts and a collection categorised as "other" (stage 4) which are presented in Table 1. Common concepts could all be described using elements from the data sets. The relevant categorised data were organised in relation to the two study questions: 1) physical activity preferences, and 2) is physical activity good for you?

To minimise bias, the elements, concepts and headings stages were also verified by an experienced senior researcher not involved in the study. It should be noted that physical activity or being physically active were intentionally not defined by the researcher because they wanted the participants' perspective of what being physically active meant to them. The results are outlined based on the assumption that physical activity preference is expressed in terms of activities most frequently engaged in by the participants.

\section{Results}

The average age of the 20 participants was 84.2 years $(S D 7.18)$ with a range of $71-102$ years; $80 \%$ were women. Two-thirds were widowed and $25 \%$ married. Ninety per cent lived in 
metropolitan Perth and two participants lived regionally in towns near Perth, $75 \%$ owned their own home and $15 \%$ lived in a retirement village. Forty per cent of participants had not finished high school and a further $40 \%$ had completed high school but not continued with any further education, $10 \%$ of the participants had a tertiary degree. Seventy per cent of the interviewees suffered from 1-2 chronic illness, $15 \%$ from three or more. Almost half (45\%) were overweight according to their body mass index $\left(>25 \mathrm{~kg} / \mathrm{m}^{2}\right)$, and $75 \%$ had problems with their mobility.

\section{Physical activity preferences in later life}

Thirteen interviewees said walking was the current activity they engaged in. This took a number of forms, such as consciously getting up from the chair and walking around the house (either inside or out), or going to the shops as described by participantseven if you have to stand to read or do anything, I'll get up then and I'll walk around, I won't sit for long (87 year old female);

yes I make a point of doing that (walking every day) also when I sit watching tele in the day, which I sometimes do, I make a point of getting up, I don't sit ...for an hour and a half, or an hour, I would get up and walk into the kitchen and back, I'm aware of all that (88 year old female - a);

walking to the shops to pick up groceries, I like the pram because you've got double support on the arms, you're not one sided and apart from that it's my shopping, I can put the shopping actually in it, it's much better than pulling those trolleys . . that's not bad for nearly 102 is it? (102 year old female). 
Or going for a walk around the neighborhood participants stated:

we go as far as we can in a quarter of an hour and then we come back... we go round the estuary, we've got a beautiful walk there, it's absolutely magnificent (84 year old male);

I used to just go up and down the street there and my son said you've got to go round the block, so on Saturday he came I thought oh I know what's going to happen he's going to make me walk the block and I had to walk the block and I could, I did it so I have done it every morning since (88 year old female - c).

After walking, gardening (including outside jobs, such as sweeping) (n=11) and housework $(n=6)$ were the next most prevalent activities identified. Some talked about outside chores around the house being included in their daily routines

I have to make breakfast and do all my chores and then oh before I come in I sweep all the outside of the house, front and back and all the leaves (88 year old female - c);

I call housework the best activity, you can have all your yoga and what have you [sic] there's more exercise in house work than anything (102 year old female);

Oh yes walking first, gardening second. That's what I enjoy most (73 year old female).

Almost a third of interviewees described doing some kind of exercises that had been prescribed by a physiotherapist, nurse or doctor, often after a fall or injury. Many had completed 
them assiduously at the time, however few continued them over the long term to assist with staying independent.

I've been very slack, I've only been doing bed exercises and then the last two or three months I haven't even been doing them properly. I do them spasmodically (73 year old female).

Many participants $(n=17)$ were also involved in other activities described as keeping

them mentally active. Some talked about doing more mental activities because their body could no longer cope with the physical ones. For example,

I was always doing something, I've always been a knitter or I do crossword puzzles or I read, I like to keep my mind active if I can't get my body going (87 year old female).

\section{Is physical activity good for you?}

All participants were asked how important they thought being physically active was. All but one $(n=19)$ replied that this was very important and often stopped them thinking about negative happenings in their lives or feeling sorry for themselves for example, oh gee it is terribly important [being active] because it takes your mind away from the traumas (77 year old female).

Some $(n=3)$ also proposed that being mentally active was just as important and that both mental and physical activity were needed to lead a happy and healthy life. Seventeen participants were involved in some kind of social or mentally challenging activity on a regular basis.

I think it is as important as [being physically active] being mentally active as well (85 year old female). 
Having identified that being physically active was important, the participants were then asked where they had learnt this. Many were not sure and suggested they just knew it $(n=11)$, that it was in their blood to be active or they just thought activity was a natural part of life. For example,

if I didn't have any physical exercise and I just sat there ... I would probably go beyond repair (71 year old male).

Five participants said that a health professional (diabetic educator, nurse, physiotherapist (at a falls clinic) and doctor) had explained to them that being physically active was important. As the neurologist said if you don't use it you lose it, you know they preach that at you; the local GP says you know, are you still walking, what are you doing? (88 year old female - a).

Watching television $(n=3)$ and reading the newspaper $(n=2)$ were the two forms of media mentioned as promoting the importance of physical activity. When participants talked about the media some mentioned being preached at

I get a bit cross, they preach it so much [being healthy and active] on the air, in the paper ... and they indicate that if you do all these things you'll live forever and it's not necessarily so (88 year old female - a),

yet others felt the advertisements helped get them moving, the advertisements on TV about it [physical activity] they've really affected me . . if it wasn't for the advertisements, I might just sloth a bit more than I do (82 year old female). 
Two participants described family members trying to encourage them to do less to avoid a fall or injury, but those who described this said they ignored the requests because they thought that if they stopped doing things they would become a burden on their families, something they were trying to avoid.

My families are always at me not to do this and not to do that, but I don't listen ... if I'm unable to do certain chores I think I am just a liability (86 year old male), and

well you become a burden, that's the last thing you want to be is a burden and that's a worry you know. . you can't just sit (96 year old female).

Incidental exercise through walking, gardening and housework has been a theme throughout the latter years of many of these participants and one acknowledged this as follows I know full well that exercise is essential, it's essential, so what did I do because I know that, I've cancelled my cleaning lady. I do all my own cleaning and I go shopping and when I go shopping I make myself go the longest way round with the trolley... it's not much but I do that ... I look after myself, I don't have any help, cancelled the help (82 year old female).

\section{Discussion}

The aims of this study were to identify the physical activity preferences of older home care clients and to explore whether these older home care clients viewed physical activity as important or not. Physical activity was purposefully not defined in order to gain a better understanding of what being physically active meant to these people. 
Walking was the predominant form of physical activity undertaken. This finding is parallel to previous studies that explored physical activity preferences of older people (Grossman and Stewart 2003; Belza, Walwick et al. 2004; Lowe, Watanabe et al. 2010), although not specifically older home care clients. Due to the popularity and well-established benefits of walking, it is suggested that organisational policy and practice and those delivering services to older home care clients, such as community nurses, should focus on the promotion of walking for this population.

Other physical activity preferences included household chores and gardening. These findings also are similar to other studies that have shown gardening and housework to be popular activities for older people in general (Townsend, Bhatnagar et al. 2012; Welmer, Morck et al. 2012). Although gardening and housework was the activity of choice for these home care clients, many older people receiving home care services find gardening or housework difficult and require practical support in order to continue being active through these means. This can take the form of helping someone find an easier way of approaching a task or using an aid or equipment. Such equipment may include kneeling pads with handles to assist in getting up after weeding; raised garden beds to make it easier to maintain the garden; a light weight vacuum; or, a long handled brush. Task redesign could include doing small amounts of housework or laundry each day to conserve energy rather than trying to do it all on just one day; using a laundry basket on wheels to avoid having to carry it; and lowering the height of the washing line. Such recommendations being made by the community nurse (or other care provider) rather than by family, could be more likely to result in uptake or continuation of activity, although further research is needed to determine whether this is the case.

The World Health Organisation's physical activity guidelines include household chores and gardening among their recommended activities for older people (World Health Organisation 
2010). However, this recommendation is only in the longer version of the guidelines and may not be known or promoted to doctors, nurses, health care workers and older people. It is essential that health and community care professionals and providers are aware of older people's preference for daily living activities, such as housework (Welmer, Morck et al. 2012) and gardening (Brown, Fuller et al. 1999) rather than other types of exercise, if they are to assist older people to maintain their strength, mobility and balance as they age.

Traditionally, activity programs for older people consist of a prescribed number of exercises to be completed a set number of times each day and/or week to improve their health. Often, as reported by interviewees in this study, these exercises are completed religiously during the brief time period when seeing the health practitioner but are not maintained over the longer term. The use of a lifestyle activity program to improve strength, balance and mobility may well be a more effective option, as this sort of program incorporates exercises into daily activities such as gardening, cleaning and housework.

Clemson et al (2010) developed a lifestyle activity program (LiFE) which incorporates exercises into everyday activity. The LiFE program includes seven activities to challenge balance and six to improve strength in the lower limbs (Clemson, Singh et al. 2012). Examples of activities include bending from the knees (rather than the waist) to pick the washing up from the basket to hang it on the clothesline, as this incorporates a squat action and improves leg strength; and standing on tip toes to reach for a mug is similar to a calf raise and improves strength in the calves and ankles. The benefits of a lifestyle activity program are that they incorporate exercising different muscle groups into everyday activities and require no additional equipment or extra time from the older person involved.

This study has demonstrated that older home care clients prefer to be active through housework, gardening and walking. It is therefore recommended that future research explore 
whether lifestyle activity programs, such as Clemson et al's (2012) LiFE program are suitable to be delivered within home care services that provide exercise programs (i.e. restorative home care services), and if they can, whether they are as effective as the exercise programs being utilised currently within restorative home care services. Most current exercise programs are structured and require the home care client to complete a set number of exercises, usually three times a day, each day of the week. These exercise programs require home care clients to find extra time within their day and are not usually maintained once the restorative home care service ends, which may mean a reduction in function over the longer term.

The importance of being physically active was acknowledged by the majority of home care clients. This was described as common knowledge, rather than having been recently learned via the media or health care professionals. Some participants did however note that family members had tried to get them to slow down and be less active. This advice was typically ignored by this study's participants, unlike those described by Koo (2011) who stopped being active and expected their children to do everything for them. It must be acknowledged that the differences between the two studies may have been due to differing cultures between the two samples. However, to avoid this happening to less empowered clients, home care agencies and health care professionals, such as community nurses, need to help families of all cultures to understand the important contribution that staying physically active makes to being able to remain living independently in old age. More home care services need to include and promote physical activity to their older clients and families. The role of community nurses, physiotherapists and occupational therapists is important in not only promoting physical activity to their older clients but making family members aware of the benefits their older relative will gain by being active. Exercise programs that are evidence based and have been trialled with this population are needed, and the results made available to community nurses and allied health 
staff. Currently the federal and state governments fund home care services in Australia and few of these services promote preventive health, particularly increasing physical activity to maintain independent living. However, the proposed aged care reforms are about encouraging wellness and enhancing older people's independence and wellbeing and therefore can be expected to include a greater emphasis on exercise and health promotion strategies. Research is needed to identify the most cost effective strategies for promoting exercise to home care clients.

One limitation of this study was that the majority of the sample was female and therefore the results may be less applicable to males. However, the majority of older people receiving home care services in Australia are women (63\%) and therefore the sample (80\%) did reflect this (Australian Institute of Health and Welfare 2007). Another limitation is that the research took place using only one community care organisation. However, there is no reason to believe that the home care clients involved in the study differed from home care clients throughout Australia.

\section{Conclusion}

This study identified the physical activity preferences of older people receiving home care services and found walking was their activity of choice, along with gardening and household chores. Health and community care agencies need to consider these findings because many home care services in Australia clean and garden for people rather than assisting them to do it for themselves and are hence removing opportunities for the client to maintain their strength, balance, function and mobility through incidental activity. Given that older people acknowledge the importance of physical activity in maintaining health and wellbeing but, like their younger counterparts, find it hard to maintain an exercise program beyond the immediate recovery period, research is needed that compares the effectiveness of lifestyle activity programs with those currently used in standard home care. 


\section{References}

Australian Institute of Health and Welfare (2007) Older Australia at a glance: ed.^eds.). AIHW, Canberra.

Bazeley P. (2009) Analysing qualitative data: More than 'identifying themes': ed.^eds.). Research Support P/L and Australian Catholic University, pp. 6-22.

Belza B., Walwick J., Shiu-Thornton S., Schwartz S., Taylor M. \& LoGerfo J. (2004) Older adult perspectives on physical activity and exercise: Voices from multiple cultures. Preventing Chronic Disease: Public Health Research, Practice and Policy 1, 1-12.

Brown W. J., Fuller B., Lee C., Cockburn J. \& Adamson L. (1999) Never too late: Older peoples' perceptions of physical activity. Health Promotion Journal of Australia 9, 55-63.

Burton E., Lewin G. \& Boldy D. (2013) Barriers and motivators to being physically active for older home care clients. Physical \& Occupational Therapy in Geriatrics 31, 21-36.

Burton E., Lewin G. \& Boldy D. (2013) Physical activity levels of older people receiving a home care service. Journal of Aging and Physical Activity 21, 140-154.

Clemson L., Singh M., Bundy A., Cumming R., Manollaras K., O’Loughlin P. \& Black D. (2012) Integration of balance and strength training into daily life activity to reduce rate of falls in older people (the LiFE study): Randomised parallel trial. British Medical Journal 345, e 4547.

Clemson L., Singh M., Bundy A., Cumming R., Weissel E., Munro J., Manollaras K. \& Black D. (2010) LiFE pilot study: A randomised trial of balance and strength training embedded in daily life activity to reduce falls in older adults. Australian Occupational Therapy Journal $57,42-50$. 
Dishman R., Heath G. \& Lee I. (2013) Physical activity epidemiology. Human Kinetics, Champaign, IL.

Gillespie L., Robertson M., Gillespie W., Sherrington C., Gates S., Clemson L. \& Lamb S. (2012) Interventions for preventing falls in older people living in the community. Cochrane Database of Systematic Reviews Issue 9. Art. No.: CD007146.

Grossman M. \& Stewart A. (2003) "You aren't going to get better by just sitting around": Physical activity perceptions, motivations, and barriers in adults 75 years of age or older. The American Journal of Geriatric Cardiology 12, 33-37.

Koo F. (2011) A case study on the perception of aging and participation in physical activities of older Chines immigrants in Australia. Journal of Aging and Physical Activity 19, 388417.

Liu C. \& Latham N. (2011) Can progressive resistance strength training reduce physical disability in older adults? A meta-analysis. Disability and Rehabilitation 33, 87-97.

Lowe S., Watanabe S., Baracos V. \& Courneya K. (2010) Physical activity interests and preferences in palliative cancer patients. Support Care Cancer 18, 1469-1475.

Michael Y., Lin J., Whitlock E., Gold R., Fu R., O’Connor E., Zuber S., Beil T. \& Lutz K. (2010) Interventions to prevent falls in older adults: An updated systematic review. Evidence synthesis No. 80. AHRQ Publication No. 11-05150-EF-1. : ed.^eds.). Agency for Healthcare Research and Quality, Rockville, MD.

Paterson D. \& Warburton D. (2010) Physical activity and functional limitations in older adults: A systematic review related to Canada's physical activity guidelines. International Journal of Behavioral Nutrition and Physical Activity 7, 1-22.

Productivity Commission (2011) Caring for Older Australians, Report No. 53, Final Inquiry Report: ed.^eds.). Commonwealth of Australia, Canberra. 
Robertson R., Robertson A., Jepson R. \& Maxwell M. (2012) Walking for depression or depressive symptoms: A systematic review. Mental Health and Physical Activity 5, 6675.

Ryburn B., Wells Y. \& Foreman P. (2009) Enabling independence: Restorative approaches to home care provision for frail older adults. Health and Social Care in the Community 17, $225-234$.

Saarloos D., Nathan A., Almeida O. \& Giles-Corti B. (2008) The baby boomers and beyond report: Physical activity levels of older Western Australians 2006: ed.^eds.). Western Australian Government, Perth: Western Australia.

Townsend N., Bhatnagar P., Wickramasinghe K., Scarborough P., Foster C. \& Rayner M. (2012) Physical activity statistics 2012: (B. H. Foundation ed.^eds.). British Heart Foundation, London.

Washburn R., McAuley E., Katula J., Mihalko S. \& Boileau R. (1999) The physical activity scale for the elderly (PASE): Evidence for validity. Journal of Clinical Epidemiology 52, 643 651.

Washburn R., Smith K., Jette A. \& Janney C. (1993) The physical activity scale for the elderly (PASE): Development and evaluation. Journal of Clinical Epidemiology 46, 153-162.

Welmer A., Morck A. \& Dahlin-Ivanoff S. (2012) Experiences of physical activity among people 80 years of age and older; Physical activity means of counteracting disability, balanced in relation to frailty. Journal of Aging and Physical Activity 20, 317-331.

World Health Organisation (2010) Global recommendations on physical activity for health: ed.^eds.). World Health Organisation, Geneva, Switzerland. 
Figure 1. Interview Schedule

- You noted in the questionnaire that you participate in (name the activities)

$\circ$ What are your reasons for being involved?

- Were you physically active as a child and through your young adult years?*

oIf yes what activities?

oHow often did you do these (per week)?

oWhy were you involved?

- Were you physically active through your later adult years up until now?

oIf yes what activities?

oHow often did you do these (per week)?

oWhy were you involved?

- Were your parents physically active as you grew up?*

oIf yes what activities?

oHow often

- You mentioned a number of things helped keep you physically active, can we discuss these in more detail? Ask about each factor from questionnaire question 24*

- You also mentioned a number of reasons that were stopping you becoming active could we discuss these in more detail? Ask about each factor from questionnaire question $25^{*}$

- How important do you think being physically active is?

oWhy?

Questions were added or adjusted as the interview progressed depending on the interviewees responses.

Note. *A number of questions were asked as part of the larger study and were not included in this study 
Table 1 Common Concepts

\begin{tabular}{|c|c|}
\hline Common Concepts & Included in this Study \\
\hline Injury and illness & $\begin{array}{l}\text { No (but did provide insight as to reasons for } \\
\text { being active or not) }\end{array}$ \\
\hline Learning physical activity is good for you & Yes \\
\hline Aspects stopping physically active & Yes \\
\hline Physical activity undertaken now & Yes \\
\hline Other activities undertaken recently & Yes \\
\hline Physical activities as a child & $\begin{array}{llll}\text { No (but did } & \text { provide } & \text { background } \\
\text { information) }\end{array}$ \\
\hline Physical activity with the family & $\begin{array}{l}\text { No (but did provide background } \\
\text { information) }\end{array}$ \\
\hline Physical activity as an adult & Yes \\
\hline Nutrition & No \\
\hline Home care services & No \\
\hline Other & No \\
\hline
\end{tabular}

